\title{
Prevalence of Alpha and Beta-Thalassemia Mutations Among Carriers of Thalassemia in Shadegan City, Southwest of Iran
}

\author{
Amin Doosti Irani ${ }^{1}$; Zahra Cheraghi ${ }^{1, *}$; Saied Bitaraf ${ }^{2}$; Parvin Cheraghi $^{3}$; Saeid Safiri ${ }^{4}$ \\ ${ }_{1}^{1}$ Department of Epidemiology and Biostatistics, Faculty of Public Health, Tehran University of Medical Sciences, Tehran, IR Iran \\ ${ }^{2}$ General Physician, Ahvaz Jundishapur University of Medical Sciences, Ahvaz, IR Iran \\ 3 Department of Public Health, Faculty of Health, Hamadan University of Medical Sciences, Hamadan, IR Iran \\ ${ }^{4}$ Department of Public Health, Faculty of Health, Hamadan University of Medical Sciences, Hamadan, IR Iran
Research Center for Modeling in Health, Institute for Futures Studies in Health, Kerman University of Medical Sciences, Kerman, IR Iran \\ ${ }^{*}$ Corresponding author: Zahra Cheraghi, Department of Epidemiology and Biostatistics, Faculty of Public Health, Tehran University of Medical Sciences, Tehran, IR Iran. \\ E-mail: cheraghiz@ymail.com
}

Received: March 2, 2015; Revised: April 26, 2015; Accepted: April 28, 2015

\begin{abstract}
Background: We aimed to investigate the alpha and beta-thalassemia mutations and assess the association of hematologic indices with mutations.

Patients and Methods: In this cross sectional study, we assessed 275 suspected thalassemia carriers. Amplification refractory mutation system-polymerase chain reaction and Gap PCR were used for detection of mutations.

Results: CD 36 - 37 (-T) and - $03.7 / \alpha \alpha$ were most common mutations. Mean of corpuscular hemoglobin and corpuscular volume was less among beta-thalassemia carriers in comparison to alpha-thalassemia carriers $(\mathrm{P}=0.001)$.

Conclusions: Detected mutations were different from other regions in Iran. After iron therapy, mean of corpuscular volume (MCV) was $<$ $69 \mathrm{fL}$ and mean of corpuscular hemoglobin was $<23 \mathrm{pg}$, may be classified as beta-thalassemia carriers.
\end{abstract}

Keywords: Alpha-Thalassemia; Beta-Thalassemia; Mutation; Prevalence; Iran

\section{Introduction}

Thalassemia is the most common monogenic disease. This disease with more than 200 different mutations has a complex genetic [1]. There is a decrease in the synthesis of globulin chains in this disease. Two common types of alpha thalassemia and beta-thalassemia are caused as a result of deficiency of alpha and beta chains [2]. Thalassemia is unevenly distributed in Iran and varies considerably from area to another area $[3,4]$. Until now, more than ten types of beta-thalassemia mutations are reported in Iran [5-8].

The screening program in Iran is the performed according to the instructions of the ministry of health and medical education. Thalassemia screening procedure is done as follows: first, the mean of mean corpuscular volume (MCV) and mean corpuscular hemoglobin (MCH) is measured in male. If both of these two indicators, respectively, are less than $80 \mathrm{fL}$ and $27 \mathrm{pg}$, then the female will be tested similarly. If both of these two indicators in female are less than expected, then HbA2 level in both sexes will be measured using column chromatography. If $\mathrm{HbA} 2$ level in both male and female are measured between 3.5 and 7, they will be thalassemia carrier couples and will be referred for genetic counseling [9].

Awareness of distribution and dispersion of thalassemia mutations is necessary for the prevention planning [6].
We aimed to investigate the alpha-thalassemia and betathalassemia mutations in southwest of Iran and assess the association between hematologic indices dealing with thalassemia mutations in carriers will be examined.

\section{Patients and Methods}

We conducted a cross sectional study on carriers of thalassemia which referred for prenatal diagnosis (PND) test, from April 2011 to November 2012 in Shadegan. All suspected to carriers of thalassemia including 149 couples which referred to thalassemia counseling center were selected. One male refused the PND test so we assessed 297 subjects. Shadegan is one of the counties of Khuzestan province in southwest of Iran. Ninety eight percent of people in Shadegan are Arab. The carrier couples were detected through screening thalassemia tests to measure three hematological indices including MCV, MCH and HbA2 (Hemoglobin A2). MCV and $\mathrm{MCH}$ are measured using automated hematology analyzer (Sysmex k-1000 Corporation) and HbA2 is measured using column chromatography $[9,10]$. According to comprehensive screening program the PND test is performed in two steps. First, the type of mutations

Copyright (C) 2015, Zahedan University of Medical Sciences. This is an open-access article distributed under the terms of the Creative Commons Attribution-NonCommercial 4.0 International License (http://creativecommons.org/licenses/by-nc/4.0/) which permits copy and redistribute the material just in noncommercial usages, provided the original work is properly cited. 
Doosti Irani A et al.

and gene deficiency are detected in carriers. Then the sample is taken from placental villi. Any types of mutations and fetus status are diagnosed in second step [9]. The related techniques used in genetic laboratories to detect beta-thalassemia mutations include: amplification refractory mutation system-polymerase (ARMSpolymerase), polymerase chain reaction (PCR), DNA sequencing, and RFLP (restriction fragment length polymorphism). In the first reaction presence of an amplified product indicates the existence of the mutation, while in the second reaction its absence suggests existence of the mutation. Furthermore, GAP-PCR, DNA sequencing, and the strip are used to detect alpha-thalassemia mutations $[11,12]$.

The exclusion criteria for include in final analysis was the suspected thalassemia carriers, diagnosed as sickle cell carrier (Hb S) and other abnormal hemoglobin ( $\mathrm{Hb}$ $\mathrm{C}$ disease, $\mathrm{Hb}$ D disease). So carriers of sickle cell (13 subjects), Hb D disease (4 subjects), and Hb C disease (1 subject) were excluded. Finally, the statistical analysis was performed on 275 participants.

All thalassemia carrier couples were referred to genetic laboratories for PND test in Ahvaz (capital of Khuzestan province). These genetic laboratories reported the result of genetic and pre-diagnosed test to the health center of Shadegan.

The health records of carrier couples archived in Shadegan Health Center were used. After obtaining the informed consent from couples, with using a pre-designed checklist, demographic data, hematologic indexes and result of genetic test and mutation types among carrier couples or their fetus were gathered. Statistical analysis was performed by Stata-11 software (STATA Corp, College Station, TX, USA), t-test, one way ANOVA and post-hoc with $95 \%$ CI were used for data analysis.

\section{Results}

In this study 140 females and 135 males were assessed, and $62.32 \%$ ( 86 ) of females were pregnant. The mean age of participants was $26.2 \pm 6.37$ years old. The results of first PND test revealed $29.82 \%$ beta-thalassemia, $42.52 \%$ alpha thalassemia, $6.91 \%$ alpha and beta-thalassemia carriers and 20.73\% normal. CD 36 - 37 (-T) with $40.24 \%$ and $\alpha^{3.7} / \alpha \alpha$ with $55.99 \%$ were the most common mutations among beta-thalassemia carriers and alphathalassemia carriers respectively (Table 1). There was a significant difference in hematological indices among normal subjects, alpha thalassemia, beta-thalassemia carriers and both alpha and beta-thalassemia carrier together $(P=0.001)$ Table 2. According to Scheffe test, beta-thalassemia carriers in comparison to normal people had the less mean of MCH and MCV (mean difference:-4.63 and -13.76 respectively, $(P=0.001)$, and the mean of hemoglobin A2 and RBC were more than normal peoples (mean difference: 2.38 and 0.75 respectively, $(\mathrm{P}=0.001)$.
Table 1. Frequency of Beta and Alpha Mutations Among Thalassemia Carriers

\begin{tabular}{|c|c|}
\hline Mutations & Values $^{a}$ \\
\hline \multicolumn{2}{|l|}{ Beta-thalassemia mutations } \\
\hline CD $36-37(-T)$ & $39(38.61)$ \\
\hline IVSII-I (G-A) & $25(24.75)$ \\
\hline CD 8 (-AA) & $13(12.87)$ \\
\hline IVSI-110 (G-A) & $6(5.94)$ \\
\hline 25 bp del & $2(1.98)$ \\
\hline $\mathrm{CD} 6(\mathrm{Hb} \mathrm{S})$ & $2(1.98)$ \\
\hline $\mathrm{CD} 8-9(+\mathrm{G})$ & $2(1.98)$ \\
\hline Fr $8-9(+G)$ & $2(1.98)$ \\
\hline $\mathrm{Hb} \mathrm{E}(\mathrm{GAG}>\mathrm{AAG})$ & $2(1.98)$ \\
\hline$-101(C-T)$ & $1(0.99)$ \\
\hline$-28(\mathrm{~A}-\mathrm{C})$ & $1(0.99)$ \\
\hline$-88(\mathrm{C}-\mathrm{A})$ & $1(0.99)$ \\
\hline $\mathrm{CD} 36-37(-\mathrm{T}), \mathrm{Hb} \mathrm{S}$ & $1(0.99)$ \\
\hline CD 39 (C-T) & $1(0.99)$ \\
\hline $\mathrm{CD} 5(-\mathrm{CT})$ & $1(0.99)$ \\
\hline IVSI-5 (G-C), CD 36 - 37 (-T) & $1(0.99)$ \\
\hline IVSI-I (G-A) & $1(0.99)$ \\
\hline Total & $101(100)$ \\
\hline \multicolumn{2}{|l|}{ Alpha-thalassemia mutations } \\
\hline$-\alpha^{3.7} / \alpha \alpha$ & $80(58.82)$ \\
\hline$-\alpha 3^{7} \mid-\alpha^{3.7}$ & $17(12.5)$ \\
\hline$\alpha^{\mathrm{CD} 19(-\mathrm{G})} \alpha / \alpha \alpha$ & $7(5.15)$ \\
\hline a poly $\mathrm{A}(\mathrm{AATAA}>\mathrm{AATGA}) / \alpha \alpha$ & $5(3.68)$ \\
\hline$\alpha^{\text {IVSI donor site }} \alpha / \alpha \alpha$ & $4(2.94)$ \\
\hline${ }^{?} \alpha / \alpha \alpha^{b}$ & $2(1.47)$ \\
\hline$\alpha^{\mathrm{CD} 90(\alpha-\mathrm{T})} \alpha / \alpha \alpha$ & $2(1.47)$ \\
\hline$\alpha^{?} \alpha / \alpha \alpha^{b}$ & $2(1.47)$ \\
\hline$-\alpha^{3.7} \mid-\alpha^{4.2}$ & $2(1.47)$ \\
\hline 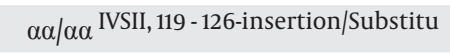 & $2(1.47)$ \\
\hline$\alpha \alpha^{2 \mathrm{Cd} 19} / \alpha \alpha^{2 \mathrm{Cd} 19}$ & $1(0.74)$ \\
\hline$\alpha^{2 \mathrm{Cd} 19} \alpha / \alpha \alpha$ & $1(0.74)$ \\
\hline$\alpha^{\mathrm{CD} 19(-G)} \alpha / \alpha \alpha$ & $1(0.74)$ \\
\hline$\alpha^{\mathrm{CD} 19-\mathrm{G}} \alpha / \alpha^{\mathrm{CD} 19-\mathrm{G}_{\alpha}}$ & $1(0.74)$ \\
\hline$\alpha^{\text {constant spring }} \alpha / \alpha \alpha$ & $1(0.74)$ \\
\hline$\alpha^{\text {Initintion } \mathrm{CD}(\mathrm{T}>\mathrm{G})} \alpha / \alpha \alpha$ & $1(0.74)$ \\
\hline$\alpha^{\text {IVSI }}$ donor ${ }^{\text {site }} \alpha / \alpha^{\text {IVSI donor site }} \alpha \alpha$ & $1(0.74)$ \\
\hline$\alpha^{\text {IVSI donor site }} \alpha /-\alpha^{3.7}$ & $1(0.74)$ \\
\hline$\alpha \alpha / \alpha$ IvsI donor site $\alpha$ & $1(0.74)$ \\
\hline$-\alpha / \alpha \alpha$ & $1(0.74)$ \\
\hline$-\alpha^{3.7} /-\alpha$ & $1(0.74)$ \\
\hline$\alpha^{3.7} \alpha / \alpha^{\mathrm{T}} \alpha$ & $1(0.74)$ \\
\hline$-\alpha^{4.2} /-\alpha^{4.2}$ & $1(0.74)$ \\
\hline Total & $136(100)$ \\
\hline
\end{tabular}

a data are presented as No. (\%)

$\mathrm{b}_{\text {?: It is mean the unknown mutation }}$ 
Doosti Irani A et al.

\begin{tabular}{|c|c|c|c|c|c|}
\hline \multirow[t]{2}{*}{ Blood indices } & \multicolumn{5}{|c|}{ Type of Mutation } \\
\hline & No mutation & Alpha & Beta Mean & Alpha and Beta & P-Value \\
\hline \multicolumn{6}{|l|}{ MCV } \\
\hline Female & $77.60 \pm 6.09$ & $74.75 \pm 5.96$ & $62.75 \pm 5.33$ & $67.58 \pm 4.90$ & 0.001 \\
\hline Male & $77.14 \pm 6.07$ & $76.11 \pm 6.10$ & $64.42 \pm 5.99$ & $69.45 \pm 7.25$ & 0.001 \\
\hline Total & $77.40 \pm 6.03$ & $75.41 \pm 6.04$ & $63.64 \pm 5.72$ & $68.62 \pm 6.22$ & 0.001 \\
\hline \multicolumn{6}{|l|}{ MCH } \\
\hline Female & $24.99 \pm 2.38$ & $24.12 \pm 2.32$ & $20.01 \pm 2.42$ & $22.31 \pm 1.71$ & 0.001 \\
\hline Male & $24.83 \pm 2.37$ & $24.54 \pm 2.36$ & $20.56 \pm 2.70$ & $22.77 \pm 2.34$ & 0.001 \\
\hline Total & $24.92 \pm 2.36$ & $24.32 \pm 2.34$ & $20.30 \pm 2.57$ & $22.57 \pm 2.04$ & 0.001 \\
\hline \multicolumn{6}{|l|}{ RBC } \\
\hline Female & $4.77 \pm 0.37$ & $5.04 \pm 0.14$ & $5.43 \pm 0.60$ & $5.22 \pm 0.65$ & 0.001 \\
\hline Male & $5.65 \pm 0.51$ & $5.79 \pm 0.47$ & $6.29 \pm 0.57$ & $6.19 \pm 0.70$ & 0.001 \\
\hline Total & $5.14 \pm 0.61$ & $5.40 \pm 0.57$ & $5.89 \pm 0.73$ & $5.76 \pm 0.82$ & 0.001 \\
\hline \multicolumn{6}{|l|}{ HbA2 } \\
\hline Female & $2.57 \pm 0.37$ & $2.60 \pm 0.53$ & $4.97 \pm 0.89$ & $5.39 \pm 0.93$ & 0.001 \\
\hline Male & $2.91 \pm 0.96$ & $2.95 \pm 1.08$ & $5.23 \pm 1.23$ & $4.87 \pm 1.30$ & 0.001 \\
\hline Total & $2.72 \pm 0.711$ & $2.77 \pm 0.86$ & $5.11 \pm 1.08$ & $5.08 \pm 1.1$ & 0.001 \\
\hline
\end{tabular}

a Values are present as Mean \pm SD

b MCV: Mean Corpuscular Volume (fL), MCH: Mean Corpuscular Hemoglobin (pg), RBC: Red Blood Cell (1012/1), HbA2: hemoglobin A2 (\%)

The mean of MCH and MCV among beta-thalassemia carriers were less than of alpha-thalassemia carriers (mean difference: -4.02 and -11.77 respectively, $(\mathrm{P}=0.001)$ and the mean of hemoglobin $\mathrm{A} 2$ and $\mathrm{RBC}$ were more than alpha carriers (mean difference: 2.33 and 0.46 respectively, $(\mathrm{P}=$ 0.001). The mean of MCH and MCV were less among peoples of $\mathrm{HbA} 2$ and $\mathrm{RBC}$ were more than of normal peoples [mean difference: $2.36(\mathrm{P}=0.001)$ and 0.62, respectively]. The mean of MCH, MCV, HbA2 and RBC among alpha-thalassemia carriers were not different significantly.

\section{Discussion}

In this cross sectional study, we assessed 275 suspected thalassemia carriers. The most common detected mutations were CD 36 - 37(-T) (40.24\%) and $-\alpha^{3.7} / \alpha \alpha$ (52.99\%) among beta-thalassemia and alpha-thalassemia carriers. Also there was a significant difference in hematological indices (MCV, MCH, RBC and HbA2) among normal subjects, alpha thalassemia, beta and both alpha and betathalassemia carrier together. Beta-thalassemia carriers in comparison to normal people had the less mean of $\mathrm{MCH}$ and MCV. Also the mean of MCH and MCV among betathalassemia carriers were less than of alpha-thalassemia carriers and the mean of hemoglobin $\mathrm{A} 2$ and $\mathrm{RBC}$ were more than alpha carriers.

Unlike the previous studies conducted in the western, northern and southern provinces of Iran, where the IVSII-1 (G-A) was the common detected mutation $[5,8,13$,
14], the most common detected mutations in our study were CD 36 - 37 (-T) and $-\alpha^{3.7} / \alpha \alpha$. The mutations reported in these studies are associated with diversity of mutation types in different geographical regions in Iran. Nonetheless it appears IVSII-1 (G-A) mutation is common mutation in north and south of Iran.

The mean of MCV was 77.40 in healthy participants, 75.41 in alpha-thalassemia carriers, and 63.64 in betathalassemia carriers. Also, we found the remarkable significant difference in the means of $\mathrm{MCV}, \mathrm{MCH}$ and $\mathrm{HbA} 2$ among alpha and beta-thalassemia carriers. The mean differences of MCV, MCH and $\mathrm{HbA} 2$ in alpha-thalassemia carriers in comparison with normal peoples were not significant. This issue is related to the importance of genetic tests to detect the types of alpha-thalassemia mutations.

In a study that conducted by Behfar et al. [15] the means of MCV, MCH and HbA2 were reported 64.18 \pm 4.67, $21.10 \pm$ 2.09 and $5.10 \pm 0.96$, respectively. The results of this study are approximately similar with our results. The slight difference between two studies may be due to the lower sample size in our study (275 subjects) in comparison 1.206 subjects in Behfar's study. After two-by-two tests of mean difference, the means of MCV and MCH among beta-thalassemia carriers were significantly lower than healthy people and alpha-thalassemia carriers. This study had some limitations. We had missing data in other hematological indices including hemoglobin $\mathrm{F}$, hemoglobin $\mathrm{A} 1$ and hemoglobin B. Therefore we could not assess the association between these indices and the types of thalassemia muta- 
tions. Our study was conducted in southwest of Khuzestan province and the finding may not be generalized to other regions and nations. Therefore more similar studies should be conducted among diverse nations and regions in Iran population to arrive at a general consensus. MCV and $\mathrm{MCH}$ are considered as two main predictive indices of minor beta thalassemia carriers in comprehensive screening program in Iran. Couples are suspected to carrier of beta thalassemia provided that MCV $<80 \mathrm{fL}$ and MCV $<27$ pg, considering our finding couples are classified as beta thalassemia carries with $\mathrm{MCV}<69$ and $\mathrm{MCH}<23$ after iron therapy and as alpha carriers thalassemia with MCV $=74$ - 77 and $\mathrm{MCH}=24$ - 25. Our study was conducted on Arab nations in south of Khuzestan province and the finding may not be generalized to other regions and nations. We suggest more similar studies should be conducted among diverse nations and regions in Iran population to arrive at a general consensus.

\section{Acknowledgements}

We would like to give special thanks to health experts working at health center of Shadegan, for their help and guidance.

\section{Authors' Contributions}

Studies design: Amin Doosti Irani and Zahra Cheraghi; clinical recommendations: Saied Bitaraf; writing the first draft: Amin Doosti Irani, Parvin Cheraghi and Zahra Cheraghi; management the data collection: Saeid Safiri; analysis of the data: Amin Doosti Irani and Zahra Cheraghi. All authors commented on the final manuscript and provided critical revisions.

\section{Funding/Support}

Tehran university of medical sciences.

\section{References}

1. Weatherall DJ, Clegg JB. The thalassaemia syndromes. 4th ed.New
Jersey: Wiley Blackwell; 2001

2. Hosseini GL. Hemoglobin in health and disease. tehran: Seda press; 2005.

3. Habibzadeh F, Yadollahi M, Haghshenas M. Epidemiology and control of common disease in Iran.Tehran: Khosravi press; 2011.

4. Merat A, Haghshenas M, Pour ZM, Plonczynski MW, Harrell AN Coleman MB, et al. Beta-thalassemia in southwestern Iran. Hemoglobin. 1993;17(5):427-37.

5. Akhavan-Niaki H, Derakhshandeh-Peykar P, Banihashemi A, Mostafazadeh A, Asghari B, Ahmadifard MR, et al. A comprehensive molecular characterization of beta thalassemia in a highly heterogeneous population. Blood Cells Mol Dis. 2011;47(1):29-32.

6. Kiani AA, Mortazavi Y, Zeinali S, Shirkhani Y. The molecular analysis of beta-thalassemia mutations in Lorestan Province, Iran. Hemoglobin. 2007;31(3):343-9.

7. Najmabadi H, Pourfathollah AA, Neishabury M, Sahebjam F, Krugluger W, Oberkanins C. Rare and unexpected mutations among Iranian beta-thalassemia patients and prenatal samples discovered by reverse-hybridization and DNA sequencing. Haematologica. 2002;87(10):1113-4.

8. Rahimi Z, Muniz A, Akramipour R, Tofieghzadeh F, Mozafari H, Vaisi-Raygani A, et al. Haplotype analysis of beta thalassemia patients in Western Iran. Blood Cells Mol Dis. 2009;42(2):140-3.

9. Ministry of Health and Medical Education. Comprehensive national program guidelines and instructional texts prevention of betathalassemia.Tehran: Seda press; 2004.

10. Greer JP, Foerster J, Rodgers GM. Wintrobes clinical hematology. 12 th ed. edPhiladelphia: Williams and Wilkins; 2009.

11. Newton CR, Graham A, Heptinstall LE, Powell SJ, Summers C, Kalsheker N, et al. Analysis of any point mutation in DNA. The amplification refractory mutation system (ARMS). Nucleic Acids Res.1989;17(7):2503-16.

12. Wanapirak C, Piyamongkol W, Sirichotiyakul S, Tayapiwatana C, Kasinrerk W, Tongsong T. Accuracy of immunochromatographic strip test in diagnosis of alpha-thalassemia-1 carrier. J Med Assoc Thai. 2011;94(7):761-5.

13. Neishabury M, Azarkeivan A, Najmabadi H. Frequency of positive XmnIGgamma polymorphism and coinheritance of common alpha thalassemia mutations do not show statistically significant difference between thalassemia major and intermedia cases with homozygous IVSII-1 mutation. Blood Cells Mol Dis. 2010;44(2):95-9.

14. Karimi M, Yarmohammadi H, Farjadian S, Zeinali S, Moghaddam Z, Cappellini MD, et al. Beta-thalassemia intermedia from southern Iran: IVS-II-1 $(\mathrm{G}->\mathrm{A})$ is the prevalent thalassemia intermedia allele. Hemoglobin. 2002;26(2):147-54.

15. Behfar M, Ehsani MA, Salamati P, et al . Associations of red blood corpuscle mean volume and hematocrit with severity of betaglobin gene mutations in beta-thalassemia carriers. Sci J School Public Health Institute Public Health Res. 2011;8(4):41-9. 